\title{
INVESTIGASI TRANSIEN TEKANAN DAN TEMPERATUR SUNGKUP AP1000 DALAM KECELAKAAN SBO DENGAN SET-POINT TEKANAN PENGGUYURAN BERBEDA
}

\author{
Hendro Tjahjono \\ Pusat Teknologi dan Keselamatan Reaktor Nuklir, BATAN \\ email: hendro@batan.go.id, telp: 021-7560912, fax: 021-7560913 \\ Diterima editor: 6 Januari 2015 \\ Direvisi editor: 3 Februari 2015 \\ Disetujui untuk publikasi: 6 Februari 2015
}

\begin{abstract}
ABSTRAK
INVESTIGASI TRANSIEN TEKANAN DAN TEMPERATUR SUNGKUP REAKTOR AP1000 DALAM KECELAKAAN SBO DENGAN SET-POINT TEKANAN PENGGUYURAN BERBEDA. Reaktor AP1000 menerapkan konsep pendinginan eksternal untuk mengantisipasi naiknya tekanan akibat terjadinya kecelakaan kehilangan seluruh catu daya listrik atau Station Black Out (SBO). Mekanisme pembuangan kalor peluruhan secara pasif dilakukan melalui Passive Residual Heat Removal System (PRHRS) yang diteruskan ke In-containment Refueling Water Storage Tank (IRWST) dan selanjutnya pada sungkup reaktor. Sungkup didinginkan secara eksternal melalui konveksi alamiah pada celah udara dan melalui penguapan air pendingin yang diguyurkan di permukaan luar dinding sungkup ketika tekanan sungkup mencapai 1,7 bar sesuai set-point yang diterapkan. Dengan mekanisme ini, tekanan akan naik sampai mencapai nilai maksimum tertentu dan kemudian turun kembali ketika pendinginan sungkup sudah mulai efektif. Tujuan dari penelitian ini adalah untuk mengetahui sejauh mana pengaruh perbedaan set-point tekanan pengguyuran tersebut terhadap tekanan dan temperatur maksimum yang dicapai. Metode yang digunakan adalah dengan melakukan simulasi menggunakan model perhitungan analitik berbasis Matlab-07 pada kondisi transien yang mampu mengestimasi daya kalor yang dievakuasi, tekanan dan temperatur di dalam sungkup terhitung mulai terbentuknya uap di dalam sungkup. Hasil simulasi menunjukkan pola transien tekanan dan temperatur yang naik hingga maksimum dan turun kembali ke suatu nilai yang relatif tetap. Dengan variasi set-point mulai dari 1,7 bar hingga 5 bar, tekanan maksimum yang dicapai meningkat dari 3,5 bar hingga 5 bar dan temperatur maksimum dari $117^{\circ} \mathrm{C}$ hingga $125^{\circ} \mathrm{C}$. Dapat disimpulkan bahwa di AP 1000, dengan naiknya set-point tekanan dimulainya pendinginan eksternal melalui pengguyuran air berpengaruh menaikkan tekanan dan temperatur maksimum yang terjadi akibat SBO.
\end{abstract}

Kata kunci: Transien tekanan, set-point pendinginan eksternal sungkup, AP1000, SBO.

\begin{abstract}
INVESTIGATION OF AP1000 CONTAINMENT PRESSURE AND TEMPERATURE TRANSIENT UNDER STATION BLACK OUT ACCIDENT WITH DIFFERENT PRESSURE SET-POINTS. AP1000 reactor applying external cooling concept to anticipate the increase in pressure due to Station Black Out (SBO). Disposal mechanism of decay heat conducted through the Passive Residual Heat Removal System (PRHRS) to In-containment Refueling Water Storage Tank (IRWST) and subsequently forwarded to the reactor containment. Containment is externally cooled through natural convection in the air gap and through evaporation cooling water poured on the outer surface of the containment wall when the pressure attaints 1.7 bars according to the applied pressure set-point. With this mechanism, the pressure will increase until it reaches certain maximum value and then decrease when containment cooling already begun effectively. The purpose of this study was to determine the effect of the set-point to the maximum pressure and temperature reached. The utilized method is to perform simulations using Matlab-07 model of analytical calculations based on a transient state that is capable of estimating the power of heat evacuated and the pressure in the containment. The simulation results show the pattern of pressure and temperature transient rises to a maximum and drops back to a value that is relatively constant. With the set-point variation ranging from 1.7 bars to 5 bars, the maximum pressure varies from 3.5 bars to 5 bars and the maximum temperature varies from $117^{\circ} \mathrm{C}$ to $125^{\circ} \mathrm{C}$. It can be concluded that with increasing the set-point pressure of starting the external cooling with water, the maximum pressure and temperature increase.
\end{abstract}

Keywords: Transient pressure, containment external cooling set-point, AP1000, SBO. 


\section{PENDAHULUAN}

Ketika terjadi Station Black Out (SBO) yaitu padamnya seluruh sumber daya listrik tanpa adanya daya cadangan, maka seluruh pompa akan padam yang segera diikuti oleh padamnya reaktor. Kalor peluruhan yang masih terus diproduksi harus tetap dibuang oleh sistem pendingin untuk mencegah naiknya temperatur elemen bakar melampaui batas keselamatannya. Kejadian pemicu kecelakaan reaktor tipe PWR telah dipelajari oleh beberapa peneliti seperti Yun Wang et al. yang melakukan penelitian pada reaktor CPR1000 [1], Soon Heung Chang et al. yang meneliti respon sistem keselamatan pasif terhadap kecelakaan di luar dasar desain (Beyond Design Basis Accident, BDBA) pada kondisi SBO [2], dan juga dibahas dalam dokumen Westinghouse Non-Proprietary Class 3 dari Westinghouse AP1000 [3]. Dalam kondisi SBO yang diperpanjang, yaitu lebih dari 72 jam, beberapa peneliti juga telah melakukan investigasi seperti Ye Cheng et al. yang menelitinya untuk reaktor AP1000 [4], dan Mukesh Kumar et al. yang menelitinya untuk Advanced Heavy Water Reactor (AHWR) [5] dan Andrija Volkanovski yang membahas implikasi SBO terhadap keselamatan [6]. Kedua reaktor tersebut menggunakan sistem pendinginan pasif yang diperhitungkan mampu mengatasi kasus SBO.

Kemampuan evakuasi kalor dari sungkup secara pasif telah diteliti melalui penelitian-penelitian sebelumnya. Dari hasil penelitian Hendro Tjahjono [7] tentang kemampuan sungkup AP 1000 dalam mengevakuasi kalor melalui pendinginan pasif dengan guyuran air di permukaan sungkup diperoleh bahwa untuk setiap kondisi temperatur sungkup, terdapat suatu nilai debit tertentu yang memberikan kemampuan evakuasi daya secara maksimum. Debit yang optimal tersebut akan naik seiring dengan naiknya temperatur sungkup. Penelitian tersebut didukung program perhitungan sifat fisis uap dan udara serta program termodinamika uap yang telah dikembangkan dalam penelitian sebelumnya [8]. Wang Yan $[9,10]$ juga telah melakukan perhitungan secara numerik terhadap unjuk kerja sistem pendingin sungkup AP1000 ketika terjadi LOCA pada sisi primer. Tekanan dan temperatur sungkup dievaluasi selama 72 jam dan diperoleh bahwa tekanan sungkup mencapai maksimum pada 5,08 bar dan temperatur maksimum sebesar $148,89^{\circ} \mathrm{C}$ dengan waktu capaian yang sangat cepat yaitu kurang dari 1 jam karena uap langsung mengisi ruang sungkup dengan cepat. Hasil ini juga sesuai dengan hasil perhitungan Farzad Choobdar Rahim [11] dan Andi Sofrany et al. [12] yang menunjukkan bahwa sistem pendinginan pasif sungkup ketika terjadi LOCA mampu menahan kenaikan tekanan pada suatu nilai maksimum di bawah 5 bar absolut jika sistem guyuran air berfungsi sesuai ketentuan, yaitu setelah tekanan mencapai 1,7 bar.

Ketika terjadi SBO di reaktor AP1000, berhentinya pompa sekunder yang berfungsi sebagai pengisi air pada pembangkit uap menyebabkan turunnya permukaan air di pembangkit uap dan hal ini akan memicu penutupan katup isolasi dari sistem primer ke pembangkit uap. Dengan tertutupnya aliran ke pembangkit uap, pembuangan kalor sisa dan kalor peluruhan akan diambil alih oleh sistem keselamatan pasif, yaitu dengan terbukanya aliran air dingin dari Core Make-up Tank (CMT) menuju sisi inlet teras reaktor. CMT ini berperan untuk menyerap kalor peluruhan di awal-awal reaktor padam. Pada Gambar 1 ditunjukkan sistem keselamatan pasif dari reaktor AP1000 [3].

Selanjutnya, pembuangan kalor peluruhan dilakukan melalui penukar kalor Passive Residual Heat Removal Sistem (PRHR-HX) yang akan membuang kalor ke In-containment Refueling Water Storage Tank (IRWST). Temperatur air di dalam IRWST akan naik hingga mencapai temperatur didihnya sehingga terjadi perubahan fasa ke uap yang akan mengisi seluruh volume kosong dari sungkup. Saat ketika temperatur didih untuk seluruh air di IRWST tercapai inilah yang dijadikan saat awal pengisian sungkup dengan uap air yang menyebabkan naiknya tekanan sungkup. Dengan demikian waktu mulai naiknya tekanan sungkup ditentukan oleh volume air di IRWST yang mengalami kenaikan temperatur dari temperatur lingkungan ke temperatur didih pada tekanan sungkup (1 atmosfer di awal) dan juga volume air di CMT yang naik dari temperatur awal yang sama dengan temperatur awal sungkup ke temperatur rata-rata pendingin primer. 


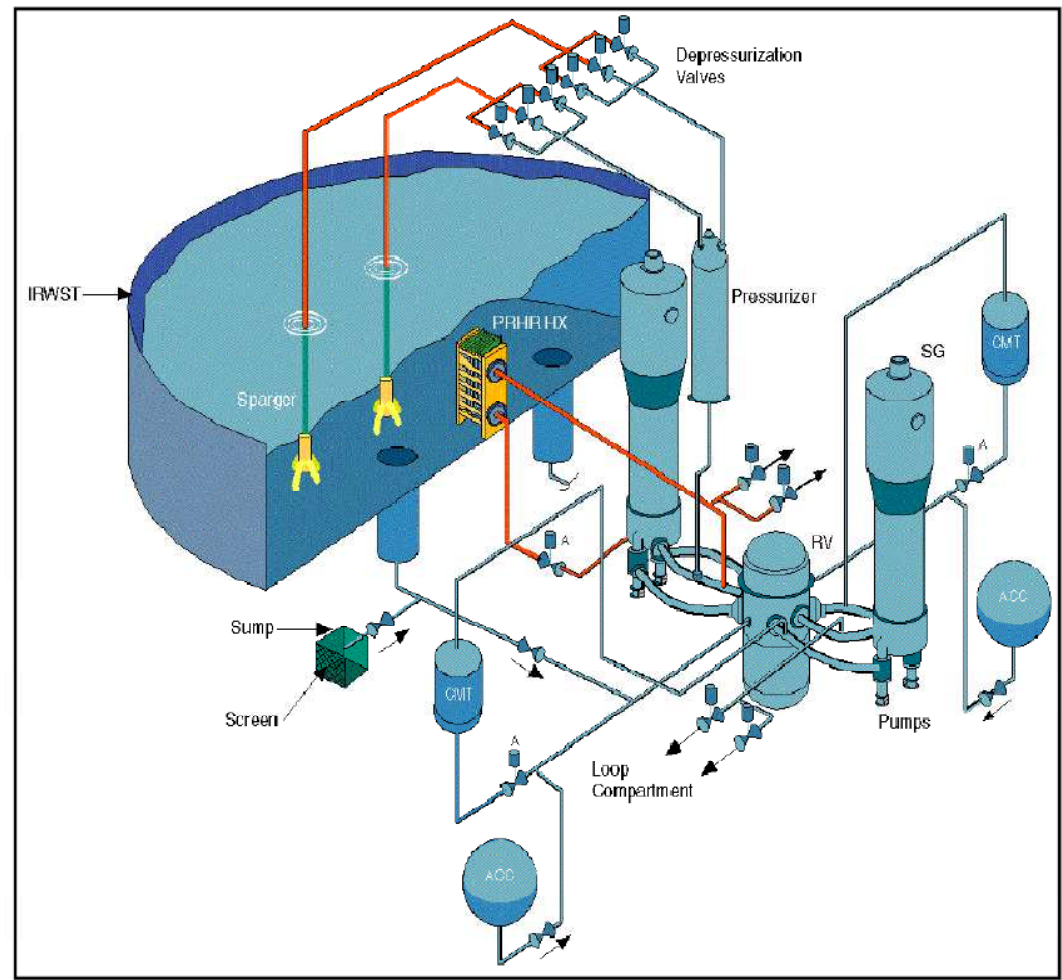

Gambar 1. Sistem keselamatan pasif pada reaktor AP1000 [1]

Di sisi lain, ketika uap mulai mengisi sungkup yang menyebabkan naiknya temperatur sungkup, terjadi juga proses pembuangan kalor melalui dinding sungkup yang akan menyebabkan terkondensasinya sebagian uap di dalam sungkup. Selama massa uap yang terkondensasi dalam interval waktu tertentu masih lebih kecil dari massa uap yang diproduksi, maka tekanan sungkup akan naik terus sebagai fungsi waktu. Massa uap yang diproduksi tergantung pada daya kalor peluruhan yang diterima oleh air di IRWST, sedangkan massa uap yang terkondensasi tergantung pada kemampuan sungkup dalam mengevakuasi kalor secara pasif, baik melalui konveksi alamiah udara yang diperkuat dengan efek cerobong di celah sungkup, maupun melalui guyuran air dari tangki Passive Containment Cooling Water Storage Tank (PCCWST) di permukaan luar sungkup bagian dalam. Dalam manajemen kecelakaan di AP1000, guyuran air mulai diberikan ketika tekanan sungkup telah mencapai 1,7 bar. Set-point tekanan awal mulai dilakukannya pengguyuran menjadi parameter penting karena bisa berpengaruh pada naiknya tekanan sungkup. Tujuan dari penelitian ini adalah untuk mengetahui sejauh mana pengaruh perbedaan set-point tekanan pengguyuran terhadap tekanan dan temperatur maksimum yang dicapai.

Metode yang digunakan adalah dengan terlebih dahulu mengembangkan suatu program perhitungan transien tekanan sungkup menggunakan bahasa pemrograman Matlab-07. Program yang dibuat ini didukung oleh program perhitungan pendinginan eksternal sungkup untuk menghitung daya evakuasi sungkup yang telah dikembangkan sebelumnya dan juga oleh program-program perhitungan sifat fisis air, uap dan udara. Dalam perhitungan ini diasumsikan bahwa isi ruang sungkup bersifat homogen sehingga nilai seluruh parameter di dalamnya bukan merupakan fungsi ruang.

\section{TEORI}

Kalor peluruhan sebagai fungsi waktu sangat bergantung kepada lamanya reaktor dioperasikan dan besarnya daya operasi reaktor dapat didekati dengan persamaan (1) yang dikembangkan oleh M. Ragheb dari University of Illinois [13], yaitu:

$$
\frac{P_{t}}{P_{0}}=6,48 \times 10^{-3}\left[t^{-0,2}-\left(t+T_{0}\right)^{-0,2}\right]
$$




\section{dengan}

$\mathrm{P}_{\mathrm{t}}=$ Daya pada saat $\mathrm{t}$ setelah reaktor padam $(\mathrm{W})$

$\mathrm{P}_{0}=$ Daya operasi reaktor sebelum padam $(\mathrm{W})$

$\mathrm{t}_{0}=$ Waktu operasi reaktor hingga padam (detik)

$\mathrm{t}=$ Waktu terhitung sejak reaktor padam (detik)

Besar energi kalor yang diperlukan untuk menaikkan temperatur air di CMT dari temperatur awal hingga temperatur rata-rata pendingin primer dapat dirumuskan dengan persamaan (2)

$$
Q_{C M T}=m_{C M T} c_{P} \cdot\left(T_{\text {primer }}-T_{C M T}\right)
$$

\section{dengan}

$\mathrm{Q}_{\mathrm{CMT}}=$ energi kalor yang diserap air pendingin CMT (Joule)

$\mathrm{m}_{\mathrm{CMT}}=$ massa air pendingin di $\mathrm{CMT}(\mathrm{Kg})$

$\mathrm{c}_{\mathrm{P}}=$ panas jenis air $(\mathrm{J} / \mathrm{Kg} . \mathrm{K})$

$\mathrm{T}_{\text {primer }}=$ temperatur rata-rata sistem primer $(\mathrm{K})$

$\mathrm{T}_{\mathrm{CMT}}=$ temperatur awal air pendingin di $\mathrm{CMT}(\mathrm{K})$

Energi ini diambil dari energi peluruhan yang diintegrasi dari daya peluruhan sesuai persamaan (3)

$$
Q_{C M T}=\int_{0}^{t 1} P_{t} d t
$$

dengan t1 adalah waktu yang diperlukan untuk menaikkan temperatur air dari CMT hingga sama dengan temperatur rata-rata pendingin primer.

Untuk memanaskan air pendingin IRWST dari temperatur awal sungkup ke temperatur didih pada tekanan sungkup diperlukan energi kalor sesuai persamaan (4)

$$
Q_{\text {IRWST }}=m_{\text {IRWST }} c_{P} \cdot\left(T_{\text {sat }}-T_{0}\right)
$$

dengan

$\mathrm{Q}_{\mathrm{IRWST}}=$ energi kalor yang diserap air pendingin IRWST (Joule)

$\mathrm{m}_{\mathrm{IRWST}}=$ massa air pendingin di IRWST $(\mathrm{Kg})$

$\mathrm{T}_{\mathrm{sat}}=$ temperatur saturasi pada tekanan sungkup $(\mathrm{K})$

$\mathrm{T}_{0}=$ temperatur awal air pendingin di $\operatorname{IRWST}(\mathrm{K})$

Dengan demikian total energi yang diperlukan untuk memanaskan air CMT dan menaikkan temperatur IRWST hingga mencapai titik didihnya adalah sama dengan energi kalor peluruhan mulai dari awal kejadian pemicu hingga air IRWST mulai mendidih, yang ditunjukkan pada persamaan (5).

$$
Q_{C M T}+Q_{\text {IRWST }}=\int_{0}^{t 2} P_{t} d t
$$

Dari persamaan (5), waktu t2 yang merupakan awal mulai terisinya sungkup dengan uap dapat dihitung.

Tekanan dalam sungkup dihitung dengan mengasumsikan uap dan udara sebagai gas ideal yang memenuhi persamaan (6).

$$
p_{s}=\left(\frac{m_{\text {uap }}}{B M_{\text {uap }}}+\frac{m_{u d}}{B M_{u d}}\right) \frac{R T_{s}}{V_{s}}
$$

dengan

$\mathrm{p}_{\mathrm{s}}=$ Tekanan sungkup $(\mathrm{Pa})$

$\mathrm{V}_{\mathrm{s}}=$ Volume ruang bebas di sungkup $\left(\mathrm{m}^{3}\right)$

$\mathrm{m}_{\text {uap }}=$ massa uap air $(\mathrm{Kg})$

$\mathrm{BM}_{\text {uap }}=$ berat molekul uap air $(\mathrm{mol} / \mathrm{Kg})$

$\mathrm{m}_{\mathrm{ud}}=$ massa udara $(\mathrm{Kg})$

$\mathrm{BM}_{\mathrm{ud}}=$ berat molekul udara $(\mathrm{mol} / \mathrm{Kg})$

$\boldsymbol{R}=$ konstanta universal gas ideal $(8,31 \mathrm{~J} / \mathrm{mol} . \mathrm{K})$

$\mathrm{T}_{\mathrm{s}}=$ temperatur sungkup $(\mathrm{K})$

Perubahan massa uap dalam suatu interval waktu $\Delta \mathrm{t}$ merupakan massa uap yang diproduksi di IRWST dalam interval waktu tersebut dikurangi massa uap yang terkondensasi di sungkup dalam interval waktu yang sama. 


$$
\Delta m_{\text {uap }}=\Delta m_{\text {produksi }}-\Delta m_{\text {kondensasi }}
$$

Massa uap yang diproduksi di IRWST dalam interval waktu $\Delta$ t dihitung sesuai dengan persamaan (8)

$$
\Delta m_{\text {produksi }}=\frac{P_{t} \cdot \Delta t}{L_{d}}
$$

dengan

$\mathrm{P}_{\mathrm{t}}=$ daya kalor peluruhan pada saat $\mathrm{t}(\mathrm{W})$

$\mathrm{L}_{\mathrm{d}}=$ kalor laten pendidihan $(\mathrm{J} / \mathrm{Kg})$

Massa uap yang terkondensasi di dinding sungkup dalam interval waktu $\Delta \mathrm{t}$ bisa dirumuskan dalam persamaan (9)

$$
\Delta m_{\text {kondensasi }}=\frac{P_{s} . \Delta t}{L_{k}}
$$

dengan

$\mathrm{P}_{\mathrm{s}}=$ daya kalor yang dievakuasi sungkup ke lingkungan pada saat $\mathrm{t}(\mathrm{W})$

$\mathrm{L}_{\mathrm{k}}=$ kalor laten kondensasi $(\mathrm{J} / \mathrm{Kg})$

Pada kondisi tekanan yang sama, nilai kalor laten kondensasi sama dengan kalor laten pendidihan.

Temperatur campuran dari dua gas yang berbeda temperatur dalam suatu ruangan bisa dihitung dengan menerapkan azas Black, yaitu kalor yang diberikan oleh gas yang temperaturnya lebih tinggi akan sama dengan kalor yang diterima oleh gas yang temperaturnya lebih rendah. Dari azas ini dapat diperoleh nilai temperatur campuran seperti dirumuskan dalam persamaan (10)

dengan

$$
T_{\text {campuran }}=\frac{m_{1} \cdot c_{P 1} T_{1}+m_{2} \cdot c_{P 2} T_{2}}{m_{1} \cdot c_{P 1}+m_{2} \cdot c_{P 2}}
$$

$\mathrm{T}_{1}=$ Temperatur gas ke-1 $(\mathrm{K})$

$\mathrm{m}_{1}=$ massa gas $\mathrm{ke}-1(\mathrm{Kg})$

$\mathrm{c}_{\mathrm{P} 1}=$ panas jenis gas ke- $1(\mathrm{~J} / \mathrm{Kg} \cdot \mathrm{K})$

$\mathrm{T}_{2}=$ Temperatur gas ke- $2(\mathrm{~K})$

$\mathrm{m}_{2}=$ massa gas $\mathrm{ke}-2(\mathrm{Kg})$

$\mathrm{c}_{\mathrm{P} 2}=$ panas jenis gas $\mathrm{ke}-2(\mathrm{~J} / \mathrm{Kg} \cdot \mathrm{K})$

\section{METODOLOGI}

Metode yang digunakan dalam menentukan parameter termal sungkup sebagai fungsi waktu adalah menggunakan metode analitik dengan mengkombinasikan persamaan-persamaan dasar termodinamika dan perpindahan kalor dengan persamaan-persamaan empiris hasil-hasil penelitian dari literatur. Pendekatan yang digunakan dalam metode ini adalah:

- Parameter termal maupun fisis dalam ruang sungkup diasumsikan homogen sehingga bukan merupakan fungsi ruang. Terkait dengan hasil penelitian Yu et al. [14] yang mengatakan bahwa di dalam sungkup terjadi stratifikasi termal, nilai parameter dalam asumsi homogen ini bisa diartikan sebagai nilai rata-rata parameter di dalam sungkup.

- Parameter fisis dalam ruang sungkup konstan dalam setiap step waktu tertentu dan merupakan fungsi temperatur.

- Diasumsikan tidak terjadi reaksi eksotermal dari uap dengan struktur, sistem dan komponen di dalam sungkup yang bisa menimbulkan sumber energi baru.

- Uap air dan udara di dalam sungkup diasumsikan sebagai gas ideal sehingga memenuhi persamaan gas ideal.

Selanjutnya, tata kerja investigasi parameter termal sungkup disusun dalam diagram alir pada Gambar 2 dengan tahapan proses dijelaskan sebagai berikut:

a. Proses perhitungan dimulai dengan mengambilan data penting yang diperlukan, yaitu:

- Data geometri mencakup volume CMT, volume IRWST, volume bebas ruang sungkup, tebal dinding sungkup, lebar celah sungkup. Data geometri terkait dari reaktor AP1000 diberikan pada Tabel 1. 
- Data sifat fisis, baik untuk air, uap, maupun udara serta dinding sungkup yang mencakup massa jenis, panas jenis, konduktivitas, kalor laten pendidihan atau pengembunan, viskositas, koefisien ekspansi.

- Data parameter termal mencakup temperatur udara, temperatur awal sungkup, temperatur awal air pendingin di CMT dan IRWST, tekanan awal sungkup, kelembaban udara.

Tabel 1. Data geometri terkait AP1000 [3,11]

\begin{tabular}{|c|l|c|}
\hline No. & \multicolumn{1}{|c|}{ Parameter } & Nilai \\
\hline 1 & Volume ruang sungkup $\left(\mathrm{m}^{3}\right)$ & 58300 \\
\hline 2 & Volume air di IRWST $\left(\mathrm{m}^{3}\right)$ & 2100 \\
\hline 3 & Volume air di PCCWST $\left(\mathrm{m}^{3}\right)$ & 3000 \\
\hline 4 & Volume air di 2 CMT $\left(\mathrm{m}^{3}\right)$ & 140 \\
\hline 5 & Tebal dinding sungkup bagian dalam $(\mathrm{m})$ & 0,0444 \\
\hline 6 & Tinggi sungkup $(\mathrm{m})$ & 65,634 \\
\hline 7 & Diameter sungkup dalam $(\mathrm{m})$ & 39,624 \\
\hline
\end{tabular}

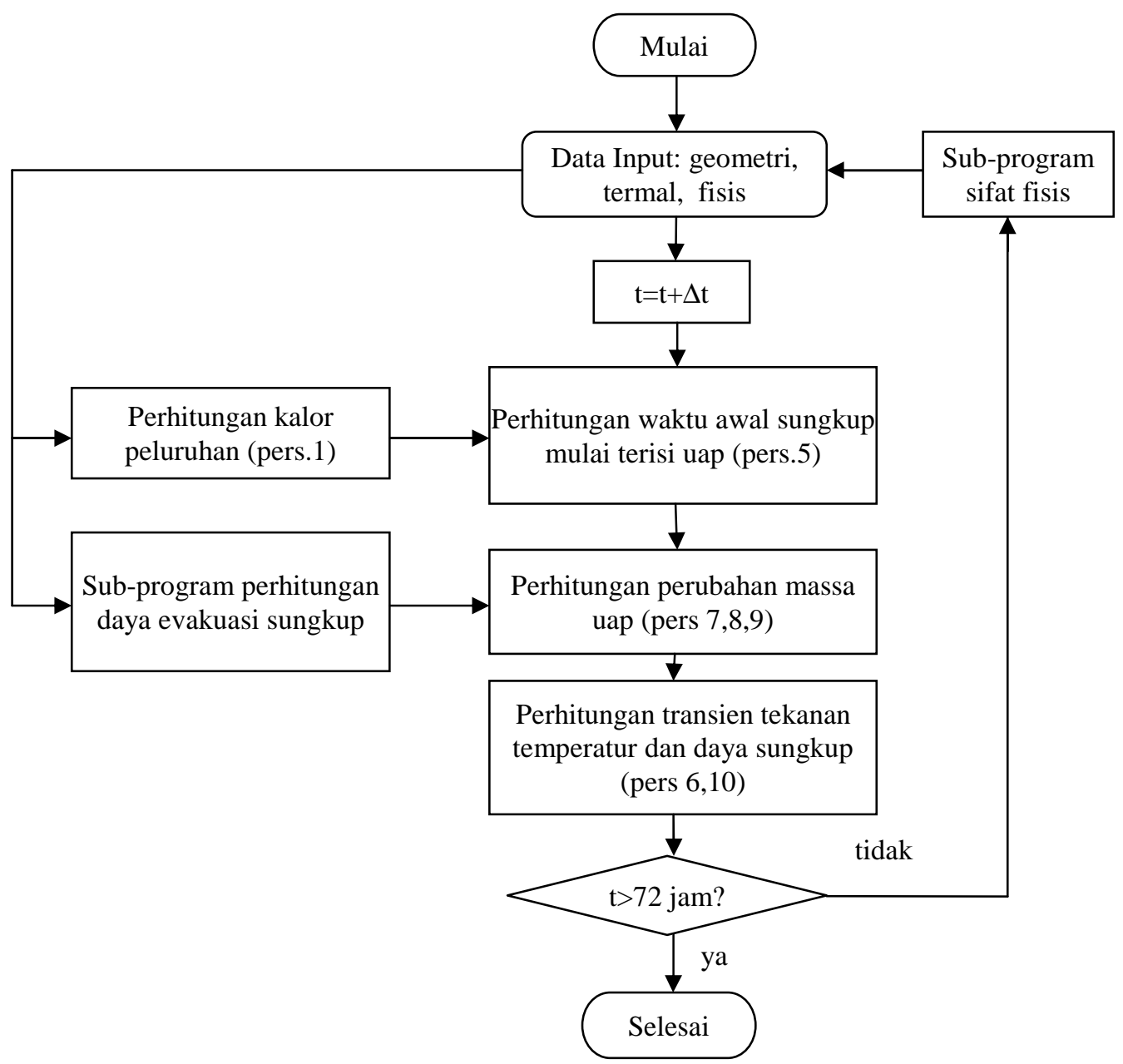

Gambar 2. Diagram alir proses perhitungan transien parameter termal sungkup 
b. Proses perhitungan waktu yang diperlukan untuk tercapainya temperatur didih air di IRWST sejak reaktor padam. Waktu yang diperlukan ini merupakan faktor penting yang menentukan karena pada saat itulah tekanan sungkup baru mulai naik. Semakin lama waktu tersebut, semakin kecil kalor peluruhan dari reaktor sehingga akan semakin kecil pula produksi uap yang dihasilkan. Perhitungan waktu ini dilakukan dengan memecahkan persamaan (5) dengan metode iteratif.

c. Proses perhitungan kenaikan efektif massa uap dalam setiap step waktu yang dihitung berdasarkan kenaikan produksi uap dikurangi dengan kondensasi uap di dinding dalam sungkup. Untuk produksi uap dihitung dengan persamaan (8) dan untuk kondensasi dihitung dengan persamaan (9). Daya untuk produksi uap dihitung dari daya peluruhan pada setiap step waktu sedangkan daya untuk kondensasi dihitung menggunakan program perhitungan evakuasi kalor dari sungkup yang telah dikembangkan melalui penelitian sebelumnya [7]. Dalam hal ini moda pendinginan eksternal sungkup bisa hanya melalui konveksi alamiah dengan celah udara berdasarkan efek cerobong, atau bersama dengan guyuran air di permukaan atas sungkup oleh sistem pendinginan sungkup secara pasif. Sistem proteksi reaktor AP1000 telah diatur sedemikian sehingga pendinginan melalui guyuran air baru diberikan setelah tekanan sungkup mencapai 1,7 bar. Sesuai dengan tujuan penelitian, pengaturan batas tekanan tersebut divariasikan dengan nilai-nilai berikut: 1,7 bar, 2,5 bar, 3 bar, 3,5 bar, 4 bar, 4,5 bar dan 5 bar.

d. Selanjutnya dilakukan perhitungan tekanan dan temperatur menggunakan persamaan (6) dan (10) dalam setiap step waktu. Dalam hal ini, baik uap maupun udara diasumsikan sebagai gas ideal yang bisa bercampur dengan sempurna. Massa udara di dalam sungkup diasumsikan tetap sepanjang waktu yang ditinjau, yaitu 72 jam, yang merupakan perkiraan waktu habisnya air di PCCWST.

\section{HASIL DAN PEMBAHASAN}

Hasil perhitungan daya kalor yang dievakuasi oleh sistem pendingin eksternal sungkup pada setpoint tekanan berbeda (1,7 bar, 2,5 bar, 3 bar, 3,5 bar, 4 bar, 4,5 bar dan 5 bar) sebagai fungsi waktu dibandingkan dengan daya kalor peluruhan ditunjukkan pada gambar 3. Terlihat dari hasil ini bahwa daya evakuasi sungkup baru mulai ada pada sekitar 9 jam setelah reaktor padam dimana uap hasil pendidihan air di IRWST mulai memasuki sungkup. Ini berarti ada tenggang waktu sekitar 9 jam sebelum kejadian SBO mulai berdampak pada sungkup. Waktu tersebut merupakan penjumlahan waktu pemanasan air di kedua CMT dari temperatur dingin ke temperatur rata-rata pendingin primer dan pemanasan air di IRWST hingga mencapai titik didihnya. 


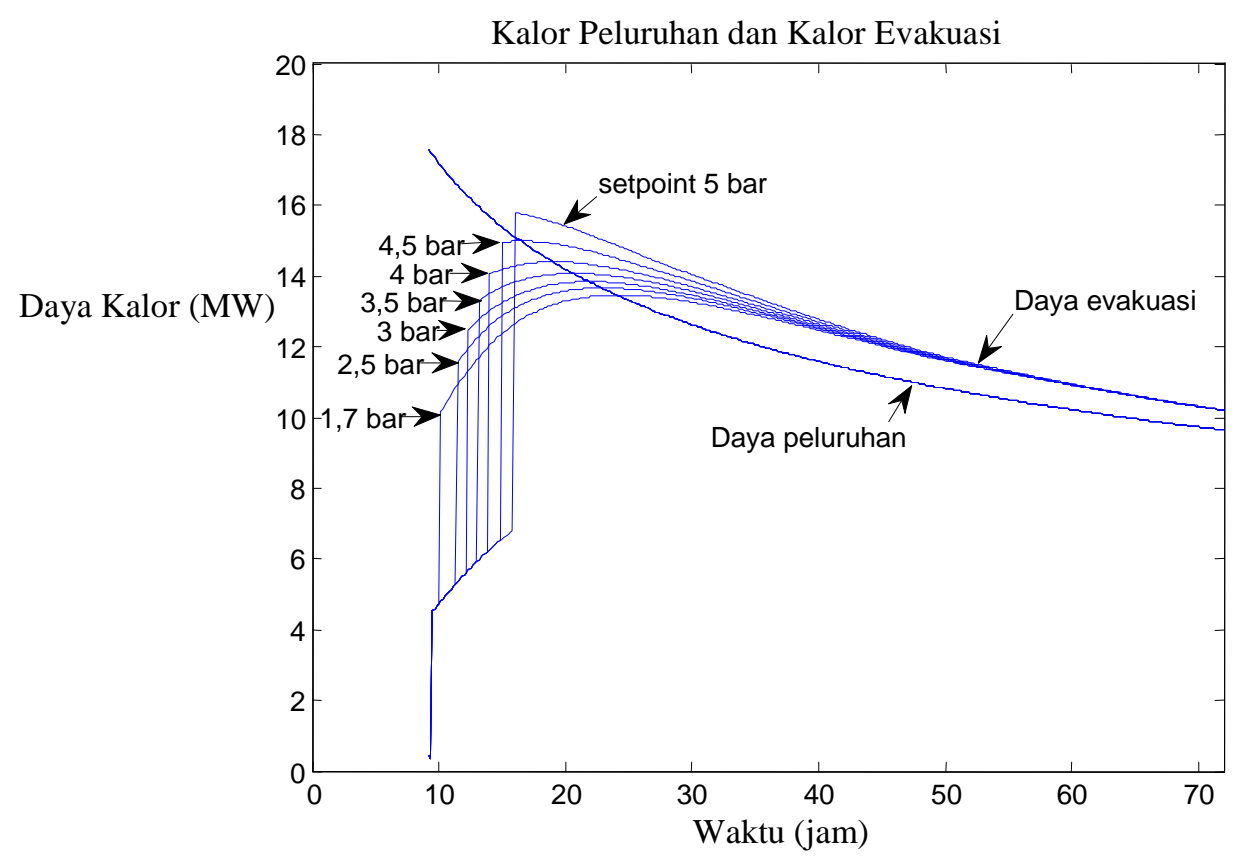

Gambar 3. Pengaruh set-point tekanan terhadap transien daya evakuasi sungkup

Pembandingan kurva antara daya evakuasi sungkup dan daya kalor peluruhan menunjukkan adanya perpotongan kurva di sekitar 25 jam untuk set-point tekanan sesuai desain yaitu 1,7 bar, waktu perpotongan ini semakin awal ketika set-point tekanan diperbesar. Sebelum titik potong tersebut, daya kalor peluruhan menunjukkan nilai yang lebih tinggi dibandingkan daya evakuasi sungkup, tetapi setelah itu berbalik daya evakuasi sungkup yang lebih tinggi. Dengan lebih tingginya daya kalor peluruhan, berarti produksi uap lebih tinggi dibandingkan dengan kondensasinya sehingga secara efektif terjadi penambahan uap sebagai fungsi waktu yang akan menyebabkan naiknya tekanan dan temperatur sungkup. Sebaliknya, ketika daya evakuasi melebihi daya kalor peluruhan, laju kehilangan uap karena terkondensasi melampaui laju produksi uap akibat kalor peluruhan. Hal ini menyebabkan laju menambahan uap bernilai negatif atau jumlah uap menurun sehingga tekanan sungkup menurun. Laju perubahan tekanan sungkup dalam hal ini sebanding dengan perbedaan nilai daya kalor antara kalor peluruhan dan kalor evakuasi sungkup. Hal ini dapat ditunjukkan pada Gambar 4 yang memberikan transien tekanan absolut sungkup dalam 72 jam untuk beberapa nilai set-point tekanan awal pengguyuran.

Untuk set-point tekanan sesuai yang digunakan di sistem proteksi AP1000, yaitu 1,7 bar, maka laju kenaikan tekanan mulai berkurang di tekanan sebesarnilai set-point tersebut dan mencapai puncak tekanan sebesar 3,5 bar di sekitar 25 jam, sehingga sungkup bisa dikatakan masih aman mengingat tekanan desainnya sebesar 5,08 bar absolut. Ketika nilai set-point dinaikkan mulai dari 2,5 bar hingga 5 bar dengan kenaikan sebesar 0,5 bar, maka terlihat bahwa nilai puncak tekanan semakin tinggi. Selain itu, tercapainya tekanan maksimum tersebut terjadi lebih cepat sesuai dengan bergesernya titik potong kurva daya kalor ke waktu yang lebih awal. Sampai dengan set-point tekanan sebesar 4,5 bar, nilai tekanan puncak masih lebih tinggi dibandingkan nilai set-point, namun di atas 4,5 bar, nilai maksimum tekanan sama dengan nilai set-point nya. Hal ini disebabkan karena ketika tekanan sungkup mencapai 5 bar, daya kalor evakuasi sudah melampaui daya kalor peluruhan (Gambar 3), sehingga pengguyuran langsung berdampak pada penurunan tekanan sungkup. 


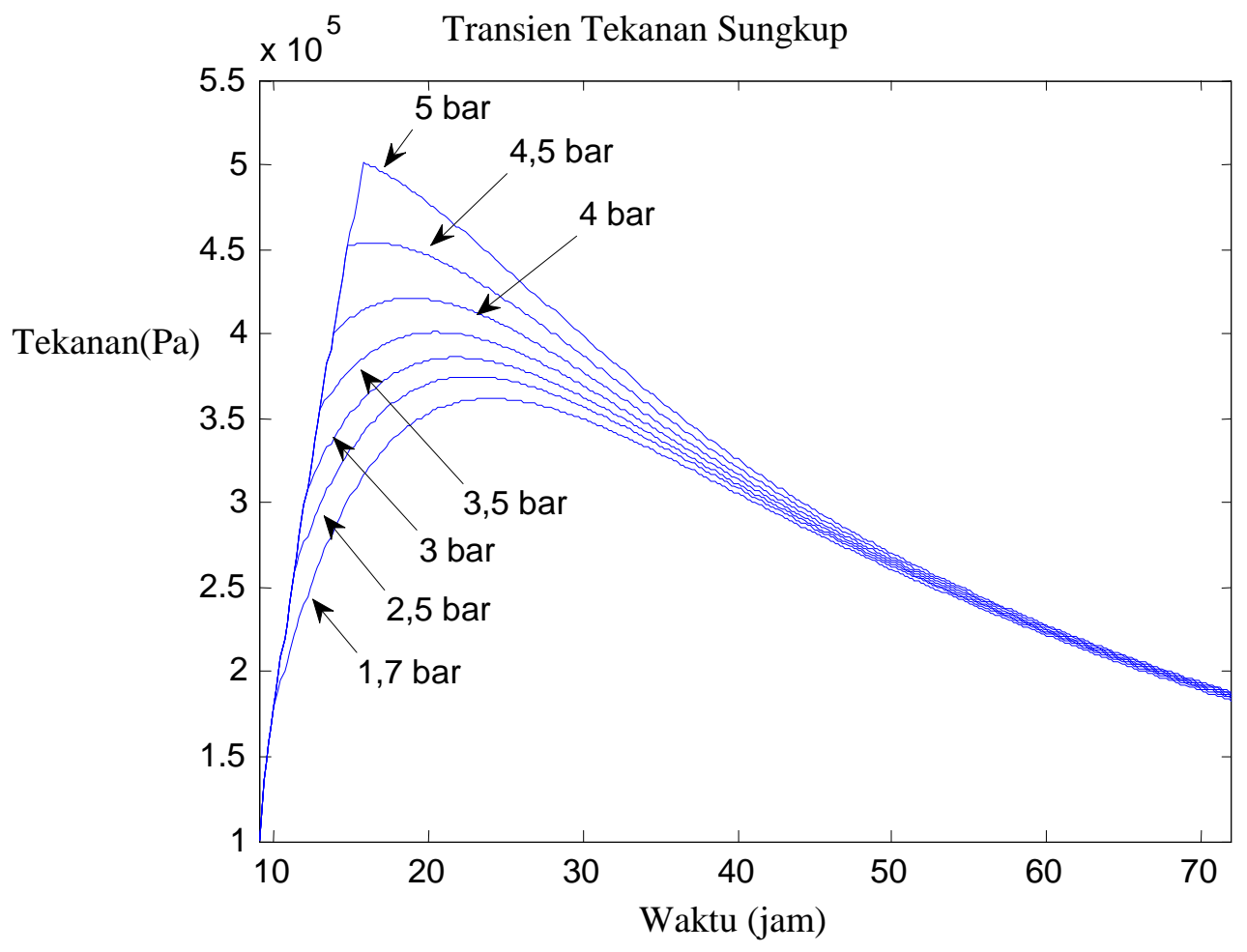

Gambar 4. Pengaruh set-point tekanan terhadap transien tekanan sungkup

Untuk masing-masing kurva juga bisa diamati bahwa ketika pengguyuran dengan air belum dilakukan, laju kenaikan tekanan lebih tinggi dibandingkan dengan setelah pengguyuran. Laju kenaikan tekanan tersebut sedikit berkurang dengan naiknya set-point tekanan. Hal ini disebabkan nilai koefisien perpindahan kalor sebelum pengguyuran dilakukan masih sepenuhnya disebabkan oleh pendinginan konveksi alamiah udara di celah sungkup dengan koefisien perpindahan kalor meningkat secara tidak signifikan dengan naiknya temperatur. Berbeda dengan ketika pengguyuran telah dilakukan, pengaruh temperatur dinding luar sungkup sangat signifikan mempengaruhi besar koefisien perpindahan kalornya, terutama akibat penguapan. Semakin tinggi temperatur, yang berarti juga semakin tinggi tekanan, maka daya kalor evakuasi juga semakin tinggi, sehingga laju kenaikan tekanan berkurang.

Pola transien temperatur sungkup serupa dengan pola transien tekanan sungkup yang ditunjukkan pada Gambar 5 dengan adanya temperatur puncak untuk setiap set-point tekanan berbeda. Nilai temperatur maksimum yang dicapai bervariasi mulai dari $117^{\circ} \mathrm{C}$ pada set-point tekanan sesuai sistem proteksi AP1000 yaitu 1,7 bar, hingga sebesar $125^{\circ} \mathrm{C}$ pada nilai set-point 5 bar. Laju kenaikan temperatur sebelum pengguyuran menunjukkan tren yang menurun, walaupun tidak signifikan, yang disebabkan oleh bertambahnya koefisien perpindahan kalor di celah udara dengan naiknya temperatur. 


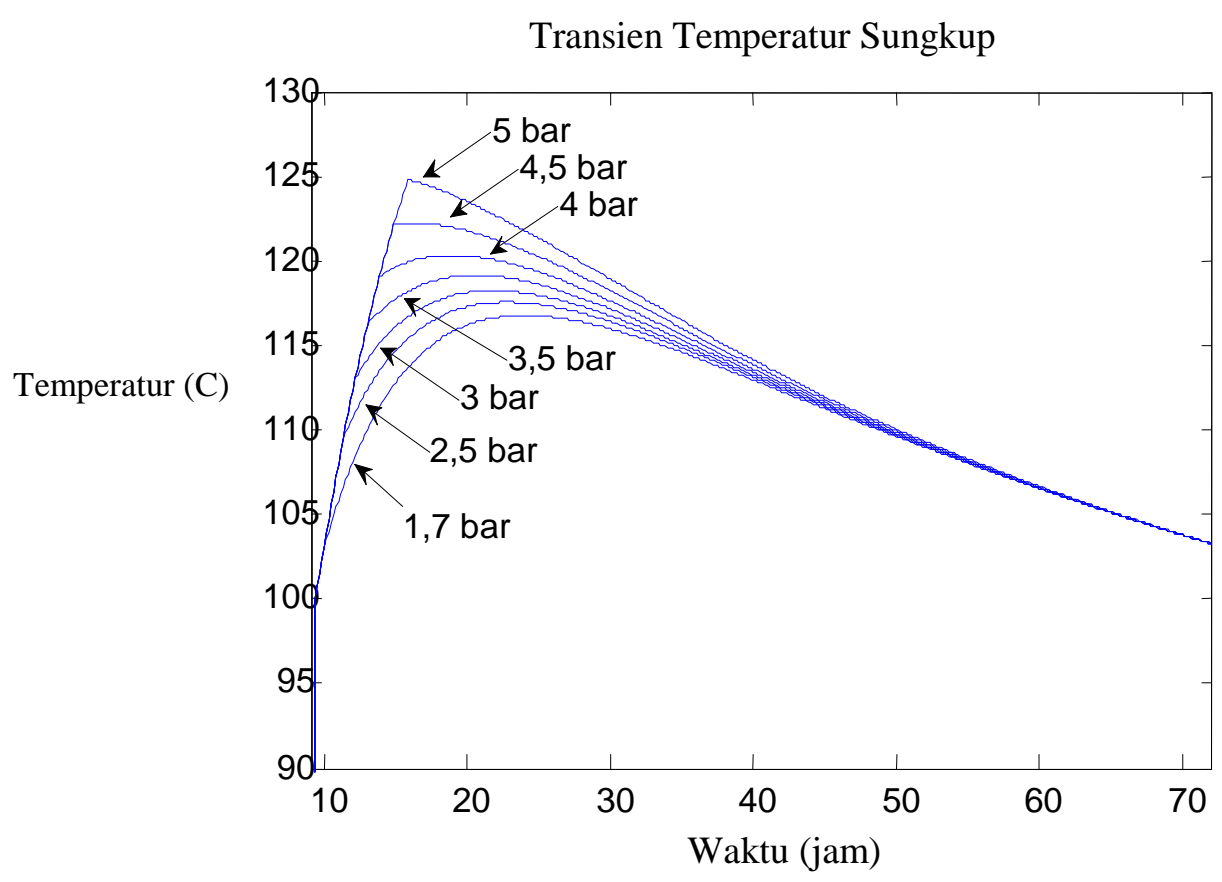

Gambar 5. Pengaruh set-point tekanan terhadap transien temperatur sungkup

Sebagai bahan pembandingan, pada Gambar 6 ditunjukkan hasil analisis transien tekanan sungkup AP1000 selama 3 hari (72 jam) untuk kondisi kecelakaan LOCA pada lengan dingin (DoubleEnded Cold Leg Guillotine, DECLG) yang dihitung dengan Code komputer SATAN-VI [15]. Pada Gambar 7 ditampilkan hasil perhitungan transien tekanan sungkup dengan program berbasis Matlab-07 untuk kecelakaan SBO dari penelitian ini (satuan tekanan disamakan dengan Gambar 6 untuk memudahkan pembandingan, yaitu dalam psig). Kedua kurva transien tekanan tersebut jelas menunjukkan pola yang berbeda satu sama lain. Pada kecelakaan LOCA besar, air primer panas yang dikeluarkan dengan cepat berubah wujud menjadi uap dan langsung mengisi ruang sungkup sehingga tekanan sungkup naik dengan cepat dan turun kembali seiring dengan dilakukannya pengguyuran. Bertahannya tekanan sungkup di atas 20 psig disebabkan karena adanya produksi uap yang terus berlangsungdengan adanya kalor peluruhan. Jadi dalam peristiwa LOCA besar, uap dalam sungkup diproduksi oleh dua macam energi, yaitu oleh entalpi tinggi dari air panas lanjut yang keluar dari lobang bocor, dan selanjutnya diproduksi oleh kalor peluruhan.

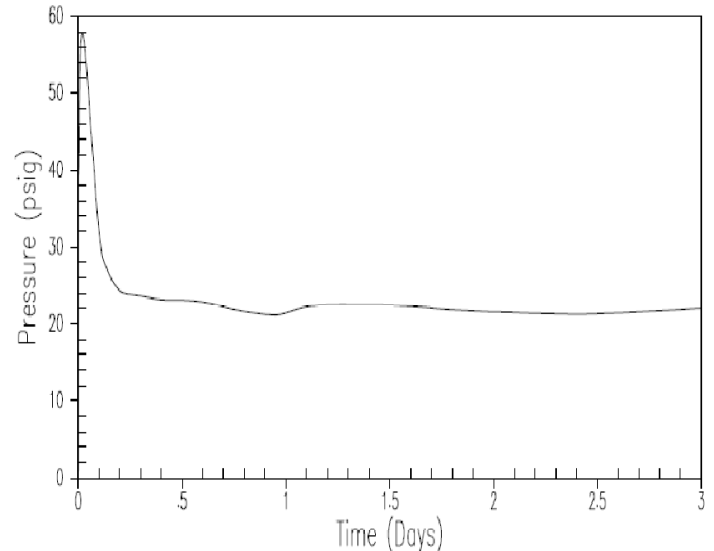

Gambar 6. AP1000 DECLG long-term LOCA (SATAN-VI code [16] )

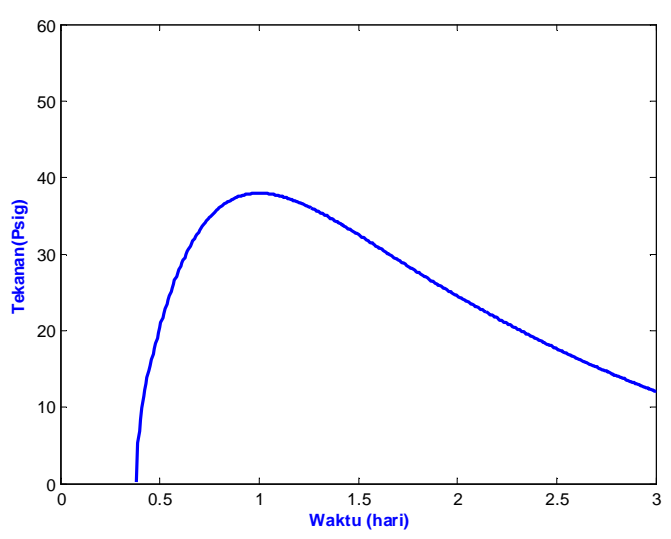

Gambar 7. AP1000 Station Black Out (Matlab07)

Sangat berbeda dengan kecelakaan LOCA yang langsung berdampak menaikkan tekanan sungkup, pada peristiwa SBO tekanan baru naik ketika pendidihan di IRWST telah dimulai. Waktu pencapaian kondisi ini relatif lama karena terlebih dahulu harus memanaskan air di CMT dan dilanjutkan dengan air di IRWST. Berbeda dengan peristiwa LOCA yang menggunakan entalpi dan 
kalor peluruhan sebagai sumber energi pemproduksi uap, sumber energi untuk pemanasan tersebut pada peristiwa SBO hanya dari kalor peluruhan saja. Jadi sangat wajar jika capaian tekanan dari peristiwa LOCA lebih tinggi dibandingkan dengan SBO.

\section{KESIMPULAN}

Dari hasil penelitian ini dapat disimpulkan bahwa pengaruh set-point tekanan untuk dimulainya pendinginan sungkup dengan pengguyuran air terhadap tekanan maksimum yang bisa dicapai sangat signifikan. Semakin tinggi set-point tekanan, atau dengan kata lain semakin ditunda pengguyuran, tekanan dan temperatur maksimum yang dihasilkan akan semakin tinggi dan waktu pencapaian nilai maksimum yang semakin cepat. Dengan variasi set-point tekanan dari 1,7 bar hingga 5 bar, tekanan maksimum yang dicapai juga bervariasi dari 3,5 bar hingga 5 bar dan temperatur maksimum bervariasi dari $117{ }^{\circ} \mathrm{C}$ hingga $125^{\circ} \mathrm{C}$. Jika dibandingkan dengan kecelakaan LOCA besar seperti DECLG, kecelakaan yang dipicu oleh SBO berlangsung lebih lambat dalam proses kenaikan tekanan dan temperatur. Besar tekanan maksimum yang dicapai juga lebih rendah dibandingkan kecelakaan LOCA besar.

\section{UCAPAN TERIMA KASIH}

Ucapan terima kasih ditujukan untuk Andi Sofrany Ekariansyah yang berpengalaman dalam analisis kecelakaan reaktor AP1000 menggunakan RELAP5, atas kesediaannya untuk berdiskusi dan memberikan saran pertimbangan terkait dampak kecelakaan baik LOCA maupun SBO terhadap karakteristik parameter termal dari sungkup reaktor AP1000 yang banyak memberikan nilai tambah dalam penelitian ini.

\section{DAFTAR PUSTAKA}

1. Jun Wang, Wenxi Tian, Yapei Zhang, Lie Chen, Longze Li, Luteng Zhang, Yukun Zhou, Guanghui Su, Suizheng Qiu. The Development of Module In-Vessel Degraded Severe Accident Analysis Code MIDAC and the Relevant Research for CPR1000 during the Station Blackout Scenario. Progress in Nuclear Energy 76 (2014) 44-54.

2. Soon Heung Chang, Sang Ho Kim, Jae Young Choi. Design of Integrated Passive Safety System (IPSS) for ultimate passive safety of nuclear power plants. Nuclear Engineering and Design 260 (2013) 104-120.

3. Westinghouse Non-Proprietary Class 3. Westinghouse AP1000 Nuclear Power Plant Coping with Station Blackout, April 2011.

4. YE Cheng, ZHENG Mingguang, WANG Yong, QIU Zhongming. Study on the Long-Term Passive Cooling Extension of AP1000 Reactor. Nuclear Science and Techniques 24 (2013) 040601.

5. Mukesh Kumar, A K Nayak, V Jain, P K Vijayan, And K K Vaze. Managing a Prolonged Station Blackout Condition in AHWR by Passive Means. Nuclear Engineering and Technology, Vol. 45 No. 5 October 2013.

6. Andrija Volkanovski, Andrej Pro sek. Extension of Station Blackout Coping Capability and Implications on Nuclear Safety. Nuclear Engineering and Design 255 (2013) 16- 27.

7. Hendro Tjahjono. Optimasi Pendinginan Eksternal pada Model Sungkup PWR-1000 menggunakan Metode Estimasi Analitik. Jurnal Teknologi Reaktor Nuklir Tri Dasa Mega, Volume 16, Nomor 2, Juni 2014.

8. Hendro Tjahjono. Analisis Transien Parameter Termal Droplet dalam Menara Pendingin PLTN. Jurnal Teknologi Reaktor Nuklir Tri Dasa Mega, Vol.11 No. 03, Oktober 2009.

9. Wang Yan. Analysis Model for the Passive Containment Cooling System, Journal of Convergence Information Technology(JCIT) Volume 7, Number 13, July 2012. 
10. Wang Yan. Preliminary Study for the Passive Containment Cooling Analysis of the Advanced PWR, Energy Procedia 39 ( 2013 ) 240 - 247.

11. Farzad Choobdar Rahim. Analysis of Containment Volume Effect on the Pressure and Temperature during LOCA in the AP1000 Reactor Containment, IJNESE Volume 2, Issue 3 September 2012, pp. 92-96.

12. Andi Sofrany Ekariansyah, Susyadi, Surip Widodo. Pemodelan Sistem Pendinginan Sungkup secara Pasif menggunakan RELAP5. Jurnal Teknologi Reaktor Nuklir Tri Dasa Mega, Vol. 14 No.3 Oktober 2012, pp. 137-145.

13. M. Ragheb. Decay Heat Generation in Fission Reactors. www.ewp.rpi.edu, Univercity of Illinois, Ragheb-Ch8-2011.

14. Yu Yu, Fenglei Niu, Shengfei Wang, Yingqiu Hu. One-Dimensional Model For Containment In AP1000 Nuclear Power Plant Based on Thermal Stratification. Applied Thermal Engineering 70 (2014) 25-32.

15. Westinghouse Electric Co. AP1000 European Design Control Document, Chapter 6: Engineered Safety Features. EPS-GW-GL-700 Revision 0, 2009. 